\title{
Peran Pengkhotbah Terhadap Minat Jemaat Menghadiri Ibadah Raya Di Gereja Injili Agape Makassar
}

\author{
Amina, Tri Supartini \\ Sekolah Tinggi Filsafat Theologia Jaffray Makassar \\ trisupartini411@gmail.com
}

\begin{abstract}
Abstrak
Tujuan penulisan ini adalah menjelaskan sejauh mana Peran Pengkhotbah Terhadap Minat Jemaat Menghadiri Ibadah Raya Di Gereja Injili Agape Makassar. Adapun metode yang penulis gunakan dalam penelitian ini adalah metode kualitatif deskriptif dengan cara mengalami (mengamati secara partisipatif), dengan menyelediki, mewancarai, bertujuan untuk menggambarkan secara utuh dan mendalam tentang realitas sosial dan berbagai fenomena yang terjadi. Dari hasil penelitian ini maka penulis menarik beberapa kesimpulan. Pertama, menjadi seorang pengkhotbah adalah tugas dan tanggung jawab yang paling mulia dari Tuhan Yesus Kristus. Oleh sebab itu seorang pengkhotbah tidak hanya menerima kepercayaan itu saja, tetapi dapat menjalankannya sebaik-baiknya sesuai dengan kebenaran firman Tuhan. Kedua, kehadiran jemaat dapat dipengaruhi oleh bagaimana caranya pengkhotbah memperisapkan dirinya dan mempersiapkan khotbahnya serta bagaimana cara pengkhotbah dapat menguraikan kebenaran firman Tuhan sesuai dengan kebutuhan jemaat yang di layaninya dan yang lain adalah perkunjungan kepada jemaat. Ketiga, kebanyakan jemaat kurang memahami bahasa inggris sehingga mereka sulit untuk memahami setiap kebenaran firman Tuhan yang disampaikan oleh pengkhotbah, hal inilah yang menyebabkan jemaat malas hadir untuk mengikuti ibadah.
\end{abstract}

Kata-kata kunci: Peran, Pengkhotbah, Minat, Jemaat, ibadah

\section{Pendahuluan}

Menyampaikan khotbah yang baik dan menarik adalah sebuah harapan dan impian bagi setiap pengkhotbah, supaya apa yang disampaikan dapat menjadi berkat buat orangorang yang mendengarkannya. Namun harus disertai dengan belajar dan mengali setiap kebenaran Firman Tuhan, dan yang terutama ialah semuanya itu harus ada dalam tuntunan kuasa Roh Kudus. Setiap khotbah yang dipersiapkan bukan saja menarik tetapi khotbah yang memiliki kuasa yang mampu menyentuh hati jemaat yang hadir mengikuti ibadah, sehingga semakin hari semakin bertambah kehadiran jemaat untuk selalu beribadah kepada Tuhan.

Karena jemaat mempunyai kebutuhan pribadi yang berbeda-beda. Mereka datang ke gereja dengan suasana hati yang berbeda-beda. ${ }^{1}$ Firman Tuhan yang di sampaikan oleh seorang pengkhotbah adalah khotbah yang telah dipersiapkan sebaik-baiknya dalam tuntunan

\footnotetext{
${ }^{1}$ Lukman Tambunan, Khotbah Dan Retorika (Jakarta: BPK Gunung Mulia, 2010), 83.
} 
kuasa Roh Kudus. Semua khotbah harus dipersiapkan dengan keyakinan bahwa Alkitab adalah firman Allah, yang memiliki otoritas karena merupakan perkataan Allah sendiri. Semua pengkhotbah harus yakin bahwa firman Allah berkuasa dan bekerja untuk mencapai tujuan Allah dalam kehidupan pribadi maupun umat Kristen.

Seorang pengkhotbah harus mengerti bagaimana caranya agar dapat memenuhi apa yang menjadi pergumulan jemaat, kerana pada dasarnya setap jemaat yang datang beribadah selalu dengan berbagai-bagai pergumulan, maka dengan demikian dalam berkhotbah seorang pengkhotbah perlu memperhatikan kebutuhan jemaat sehingga ketika berkhotbah akan membawa pengaruh bagi jemaat, Hal ini sama seperti yang ditulis oleh Lukman Tambunan, "Sebagian hadir dengan hati yang damai, tetapi sebagian lagi justru dalam suasana yang penuh dengan pergumulan, pertikaian, bahkan penderitaan."2 Jadi, berkhotbah bukan sekedar berkhotbah tetapi perlu memperhatikan kebutuhan atau pergumulan jemaat.

Berkhotbah adalah pengembangan keterampilan dasar bagi pertumbuhan gereja yang kuat dengan tujuan yaitu menimbulkan perubahan perilaku. ${ }^{3}$ Dari pemaparan di atas, jelas bahwa berkhotbah yang baik akan menimbulkan perubahan prilaku bagi jemaat dan tentunya juga akan membuat gereja bertumbuh dengan baik melalui iman maupun kerohanian jemaat.

Matthew Simpson dalam bukunya Lectures on Preaching, menempatkan seorang pengkhotbah sebagai berikut: "Mimbar adalah tahtanya, ia berdiri sebagai penganti Kristus, pesan yang di sampaikan merupakan Firman Tuhan, sekelilingnya adalah jiwa-jiwa bernilai kekal: Sang Juruselamat, yang tak nampak ada di sampingnya. ${ }^{4}$ Khotbah yang disampaikan bukanlah khotbah yang kosong artinya tidak pada sasaran yang tepat, tetapi khotbah yang memiliki makna atau isi Firman Tuhan yang mampu mengubah hati setiap jemaat yang hadir dalam ibadah tersebut.

Haddon W. Robinson, dalam bukunya berjudul Cara Berkhotbah Yang Baik, "Etos adalah seorang pengkhotbah yang menuntut kesalehan, ia mengatakan bahwa setiap pengkhotbah harus menuju mimbar dengan hati yang sudah diuji oleh Allah dan dikuduskan dengan darahNya." 5 Di sini menunjukan bahwa pengkhotbah harus menunjukkan sikap hormat pada teks yang akan dijelaskan, dengan harapan yang besar untuk mempelajari apa yang dimaksudkan setiap bagian teks tersebut, sehingga dapat menyampaikan pemahaman pesan teks pada mereka yang mendengar firman Tuhan.

Rasul Paulus menegur para pengkhotbah agar selalu rindu menyampaikan setiap kebenaran firman Tuhan kepada jemaat-jemaatnya, Paulus berkata bahwa itulah sebabnya aku ingin untuk memberitakan Injil kepada kamu juga yang diam di Roma (Roma 1:15) Rasul Petrus juga mengatakan bahwa inilah Firman yang di sampaikan Injil kepada kamu (1 Petrus 1:25) Rasul Paulus mengatakan dalam 1 Tesalonika 2:13 bahwa "kamu telah menerima Firman Allah yang kami beritakan itu, bukan sebagai perkatan manusia, tetapi memang sungguh-sungguh Firman Allah yang bekerja juga didalam kamu yang percaya. ${ }^{6}$ Paulus juga mendorong Timotius dengan seruan: beritakanlah Firman 2 Timotius 4:2.

${ }^{2}$ Lukman Tambunan, Khotbah Dan Retorika (Jakarta: BPK Gunung Mulia, 2010), 83.

${ }^{3}$ Jerry Vines \& Jim Shaddix, HOMILETIKA Kuasa Dalam Berkhotbah (Malang: Gandum Mas, 2009),

35.

${ }^{4}$ Haddon W. Robinson, Cara Berkhotbah Yang Baik (Yogyakarta: Yayasan ANDI, 2002), 8. Mengutip, Matthew Simpson, Lectures on Preaching (New York: Phillips \& Hunt, 1879), 166.

${ }^{5}$ Haddon Robinson, Craig Brian Larson, The Art \& Craft of Biblical Preaching Sumber Lengkap Untuk Komunikator Masa Kini jilid 1 (Malang: Literatur SAAT 2012), 132.

${ }^{6} 2$ Timotius 4:2(TB). 
D. Martin Lloyd-Jones, pendeta terkenal dari Westminstr Chapel Of London, Inggris, dalam karyanya Studies in the Sermon on the Mount, mengatakan bahwa khotbah bukanlah suatu karangan sastra untuk diterbitkan dengan maksud di baca berulang-ulang, melainkan suatu berita yang di maksudkan untuk di dengar dan mempunyai dampak langsung pada pendengarnya. ${ }^{7}$ Khotbah harus bebas dari ketidakjelasan dan tidak berisi materi tambahan yang tidak ada hubungan dengan tema utama, dengan kata lain khotbah itu harus disusun sedemikian rupa sehingga tidak mengalami kesulitan oleh jemaat dalam memahami firman Tuhan yang disampaikan dan pendengar mudah mengerti inti dari khotbah tersebut.

Hal ini juga yang terjadi di jemaat Gereja Injili Agape Makassar, berdasarkan data yang peneliti temukan dalam buku Pedoman Gereja Injili Agape Makassar,.

Jemaat Gereja Injili Agape Makassar adalah jemaat yang dirintis oleh bapak pendeta Bob Jokiman, yang terbentuk pada tahun 2007. Jemaat ini pada umumnya dari orangorang Chinese yang berdomisili di Makassar. Jemaat ini juga belum terlalu besar dan belum ada jumlah kartu keluarga yang jelas karna rata-rata jemaatnya belum berkeluarga. Ada juga yang sudah bercerai, ada pula yang hanya suami atau istrinya saja yang bergabung di gereja itu. Jumlah jemaat yang sebenarnya adalah 40 orang, tetapi yang setia hadir di setiap ibadah raya hanya berjumlah 30 orang saja. ${ }^{8}$

Padahal, gembala dan pengerja gereja selalu rajin untuk mengunjungi mereka, mendoakan dan memberikan penguatan dan nasehat-nasehat tentang kebenaran firman Tuhan. Namun kenyataan yang terjadi setiap minggu, semakin berkurang jemaat yang hadir untuk mengikuti ibadah. Melalui pengamatan penulis setiap khotbah yang disampaikan kebanyakan jemaat tidur atau bercerita dengan yang lainnya, mereka tidak fokus mendengarkan Firman Tuhan yang disampaikan oleh pengkhotbah.

\section{Pokok Masalah}

Sesuai dengan latar belakang masalah yang sudah penulis uraikan di atas, maka yang menjadi pokok masalah di sini adalah sebagai berikut:

Sejauh mana peran pengkhotbah terhadap minat jemaat Gereja Injili Agape Makassar dalam menghadiri ibadah raya?

\section{Tujuan Penelitian}

Adapun tujuan penulisan yang hendak di capai dalam karya ilmiah ini yaitu:

Untuk mengetahui sejauh mana peran pengkhotbah terhadap minat jemaat Gereja Injili Agape Makassar dalam menghadiri ibadah raya?

\section{Manfaat penelitian}

Yang menjadi manfaat penulisan karya ilmiah ini adalah sebagai berikut:

Pertama, memberikan gambaran kepada pengkhotbah untuk lebih meningkatkan kualitas berkhotbah bagi jemaat Gereja Injili Agape Makassar.

Kedua, untuk memenuhi sebagian syarat-syarat dalam meyelesaikan stratum 1 (S1) program studi Pendidikan Agama Kristen pada Sekolah Tinggi Theologia Jaffray Makassar.

\footnotetext{
${ }^{7}$ James Brage, Cara Mempersiapkan Khotbah (Malang: Gandum Mas, 2014), 77. Mengutip, Baird, Preparing for Platform and Pulpit (Nashville Tennessee: Abingdon Press, 1968), 67.

${ }^{8}$ Buku Pedoman Gereja Injili Agape Makassar.
} 


\section{Metode Penelitian}

Untuk mendapatkan data dan informasi berkaitan dengan karya ilmiah ini, maka penulis menggunakan metode penelitian kualitatif dengan beberapa model pengumpulan data sebagai berikut: ${ }^{9}$

Pertama, metode kualitatif dengan menggunakan teknis analisis data yang mencakup.

Kedua, menggunakan metode observasi lapangan dengan cara wawancara

Ketiga, melakukan kajian pustakan melalui buku-buku yang berkaitan dengan judul yang di bahas dalam karya ilmiah ini dan melalui internet.

\section{Batasan Penelitian}

Untuk kelancaran karya ilmiah ini, maka penulis membatasi ruang lingkup pembahasan yang di usulkan oleh penulis dalam karya ilmiah ini, hanya berfokus pada peran pengkhotbah terhadap minat jemaat menghadiri ibadah raya.

\section{Kesimpulan} berikut:

Pada akhir penulisan karya ilmiah ini penulis memberikan kesimpulan sebagai

Pertama, menjadi seorang pengkhotbah adalah tugas dan tanggung jawab yang paling mulia dari Tuhan Yesus Kristus. Oleh sebab itu seorang pengkhotbah tidak hanya menerima kepercayaan itu saja, tetapi dapat menjalankannya sebaik-baiknya sesuai dengan kebenaran firman Tuhan. Pengkhotbah tidak bisa terlepas dari belajar dan terus belajar kebenaran firman Tuhan dan dengan meminta tuntunan kuasa Roh Kudus, karena melalui belajar dan tuntunan Roh Kudus seorang pengkhotbah dapat mempersiapkan firman Tuhan dengan baik dan benar kepada jemaatnya.

Kedua, kehadiran jemaat dapat dipengaruhi oleh bagaimana caranya pengkhotbah mempersiapkan dirinya dan mempersiapkan khotbahnya serta bagaimana cara pengkhotbah dapat menguraikan kebenaran firman Tuhan sesuai dengan kebutuhan jemaat yang di layaninya dan yang lain adalah perkunjungan kepada jemaat.

Ketiga, kebanyakan jemaat kurang memahami bahasa Inggris sehingga mereka sulit untuk memahami setiap kebenaran firman Tuhan yang disampaikan oleh pengkhotbah, hal inilah yang menyebabkan jemaat malas hadir untuk mengikuti ibadah.

\section{Kepustakaan}

Adams E. Jay. Preaching With Purpose Khotbah Yang Terarah. Malang: Gandum Mas 2004.

Alwi, Hasan. Kamus Besar Bahasa Indonesia. Jakarta: Balai Pustaka, 2003.

Berhitu, Jeffray, Reinhard. "Peran Gembala Jemaat Terhadap Pengembangan Pelayanan Holistik Di Gereja Kemaha Injil Indonesia Jemaat Yegar Sahaduta Jayapura”. Jurnal Jaffray 12, no. 2, (Oktober 2014): 13-45. Diakses 25 Mei 2018. http://ojs.sttjaffray.ac.id/index.php/JJV71/article/view/19/pdf_10.

\footnotetext{
${ }^{9}$ Hengki Wijaya, Analisis Data Kualitatif Ilmu Pendidikan Teologi (Makassar: Sekolah Tinggi Theologia Jaffray, 2018), 38-42.
} 
Bridges, Jerry. Hidup Yang Berbuah. Bandung: Pionir Jaya 2008.

Brage, James. Cara Mempersiapkan Khotbah. Malang: Gandum Mas, 2014.

Daradjat, Zakiah. Kesehatan Mental. Jakarta :Gunung Agung, 1983.

Evans, William. Cara Mempersiapkan Khotbah. Jakarta: Gunung Mulia, 2015.

Effendy U, Onong. Dimensi-Dimensi Komunikasi. Bandung: Alumni 1981 Bandung, 1981.

Gunawan, Agung. "Peran Komunikasi Bagi Pertumbuhan Gereja." Jurnal JTA 10, no.19

(September 2008):1-29. Diakses 10 Mei 2018. http://sttaletheia.ac.id/wpcontent/uploads/2012/08/vol.10-no.19_2008.pdf.

Han,Yap Un. Problematika Hamba Tuhan. Manado: Yayasan Daun Family, 2004.

Harper, Steve. Pesan John Wesley Untuk Masa Kini. Michigin: Zondervan Publisging House, 1983.

Hadi, Sutrisno. Statistik. Yogyakarta: ANDI Offset, 2000.

Husaini. Metodologi Penelitian Sosial. Jakarta: Bumi Askara, 1996.

Kadarsilo, Tri. Model Alternatif Latihan Khotbah. Yogyakarta: ANDI Majalah Rohani, 2004.

K, Shipman, Michael. Pembaharuan Pelayanan Mimbar. Bandung: Kalam Hidup, 2006.

L, Teresa, Fry Brown. Menyampaikan Khotbah. Jakarta: Gunung Mulia. 2018.

L.Teresa, Fry Brown. Seri Unsur-Unsur Berkhotbah Menyampaikan Khotbah. Jakarta: BPK Gunung Mulia, 2018.

Mcpherson, Miles. Jadikan Hidup Ini Berarti. Jakarta: Light Publishing Menerangi dan Memberkati, 2009.

Nazir, Mohammad. Metode Penelitian. Jakarta: Ghalia Indonesia, 1998.

Oswald J. Sanders. Kepemimpinan Rohani. Bandung: Kalam Hidup, 2017.

Prasetya, F. Mardi. Psikologi Hidup Rohani. Yogyakarta: Kansius Anggota IKAPI, 1992.

Prime, Derek. Tanya Jawab tentang Iman Kristus. Jakarta: Yayasan Komunikasi Bina Kasih/OMF, 2006.

Quivik A, Melinda. Seri Unsur-Unsur Berkhotbah Melayankan Firman Berkhotbah Dalam Ibadah. Jakarta: Gunung Mulia, 2018.

Robinson, Haddon \& Brian. Craig, Larson, Jilid 1 the Art \& Craft of Biblical Preaching Sumber Lengkap Untuk Komunikator Masa Kini. Malang: Literatur SAAT, 2012.

Robinson, Haddon. Jilid 2 The Art \& Craft of Biblical Preaching. Malang: Literatur SAAT, 2012.

Ronda, Daniel. Prosiding Seminar Khobah Kontemporer. Makassar: Sekolah Tinggi Theologia Jaffray, 2015.

Ronda, Daniel. Khotbah Yang Berkuasa. Makassar: Kalam Hidup, 2016.

Rumahlatu, Jerry. Psikologi Kepemimpinan. Jakarta: Cipta Varia Sarana, 2011.

Salamah. "Kesiapan Mental Masuk Dunia Kerja Ditinjau Dari Pelaksanaan Pendidikan

Sistem Ganda Dan Penerimaan Bimbingan Karis Siswa SMK DI DIY”. Jurnal

Didaktika 7, no. 1. (Januari 2006):1-30. Diakses 4 Juni 2018.

upy.ac.id/digilib/journal/.../9_.pdf.

Strom, Bons. Apakah Penggembalaan Itu?. Jakarta: PT BPK Gunung Mulia, 1976.

Stanley, Andy. Visioneering. Yogyakarta: Yayasan ANDI, 2002.

Sugiono. Metode Penelitian kuantitatif dan kualitatif. Bandung: Afabeta, 2009.

Sanjaya, Wina. Penelitian Pendidikan. Jakarta: Prenadamedia Group, 2013.

Susanto, Hasan. Homiletik Prinsip Dan Metode Berkhobah. Jakarta: Gunung Mulia, 2004. 
Shaddix, Jim \& Vines, Jerry. HOMILETIKA Kuasa Dalam Berkhotbah. Malang: Gandum Mas, 2009.

Tafonao, Talizaro. "Peran Gembala Sidang Dalam Mengajar Dan Memotivasi Untuk Melayani Terhadap Pertumbuhan Rohani Pemuda".

Jurnal Teologi Injili dan Pembinaan Warga Jemaat”. Jurnal Evangelikal 2, no.1 (Januari 2018):26-49.

Takaria, Gerry C. J. "Menyelesaikan Masalah Di Antara Sesama Anggota Jemaat Berdasarkan Petunjuk Yesus Di Matius 18:15". Jurnal Koinonia, 4, no. 1 (Mei 2015):23-35. Diakses 5 Juni 2018. https://media.neliti.com/.../106314-ID--a.pdf

Tambunan, Lukman. Khotbah Dan Retorika. Jakarta : BPK Gunung Mulia, 2010.

Thom \& Schultz, Joani. Meningkatkan Kinerja Jemaat. Bandung: Kalam Hidup, 2002. Taycoy, Selvester M. Kumpulan Khotbah Yang Memberkati. Jakarta: Media Gracia, 2010.

W, Robinson, Haddon. Cara Berkhotbah Yang Baik. Yogyakarta: Yayasan ANDI Anggota IKAPI, 2002.

Williams, Pat dan Denney. Jim. Untuk Apakah Anda Hidup?. California, U.S.A: Light Publishing, 2009.

Winarto, Amos Oei, "Khotbah Yang Kontekstual Memuridkan Para Pengkhotbah Untuk Memuridkan Jemaat". Jurnal Theologi Aletheia 19, no, 12 (Maret 2017):22-22.

Diakses 11 Mei 2018. http://sttaletheia.ac.id/wpcontent/uploads/2017/04/.pdf\#page $=75$.

Warren, Rick. Untuk Apa Aku Ada Di Dunia Ini?. Jakarta: Immanuel Publishing House, 2013.

Wijaya, Hengki. Analisis Data Kualitatif Ilmu Pendidikan Teologi. Makassar: Sekolah Tinggi Theologia Jaffray, 2018.

Wijaya, Hengki (ed.). Metodologi Penelitian Pendidikan Teologi. Makassar: Sekolah Tinggi Theologia Jaffray, 2016. 